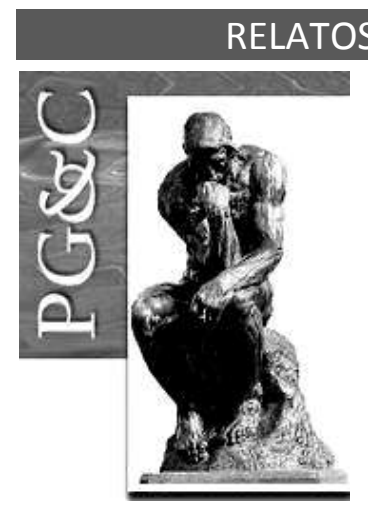

\title{
DIVERSIDADE E GESTÃO: ANÁLISE NA PERSPECTIVA DE GÊNERO E RAÇA NO BRASIL
}

\author{
Cláudia Aparecida Avelar Ferreira \\ Doutoranda em Administração pela Pontifícia Universidade \\ Católica de Minas Gerais, Brasil. \\ E-mail: claudiahgv@gmail.com \\ Ivone de Lourdes Oliveira \\ Doutora em Comunicação e Cultura pela Universidade Federal do Rio de \\ Janeiro, Brasil. Professora da Pontifícia Universidade \\ Católica de Minas Gerais, Brasil. \\ E-mail: ivonepucmg@gmail.com \\ Simone Costa Nunes \\ Doutora em Administração pela Universidade Federal de Minas \\ Gerais, Brasil. Professora da Pontificia Universidade Católica de Minas \\ Gerais, Brasil. \\ E-mail: sinunes@pucminas.br \\ Gilce Aparecida Quintão Castro \\ Doutoranda em Linguística e Língua Portuguesa pela Pontifícia \\ Universidade Católica de Minas Gerais, Brasil. \\ E-mail: gilcecastro@terra.com.br
}

\section{Resumo}

O objetivo deste artigo é discutir a questão da diversidade cultural em organizações brasileiras, no contexto de siderurgia e mineração, em relação à mulher negra nesse espaço. A metodologia aplicada se pauta na pesquisa descritiva, de caráter qualitativo, com interpretação erigida na Análise do Discurso. Como resultados, por meio da construção de sentido dos sujeitos pesquisados, mostra a complexidade da temática sobre e gênero e raça nas organizações brasileiras. Conclui que a aplicação da base teórica fundada nas dimensões da organização defendidas por Baldissera $(2004 ; 2008 ; 2009 ; 2015)$ possibilita demonstrar como a organização falada e comunicante é complexa, como os estudos sobre diversidade cultural.

Palavras-chave: Gênero. Raça. Comunicação Organizacional. Mulher Negra. Gestão.

\section{DIVERSITY AND MANAGEMENT: \\ ANALYSIS IN THE PERSPECTIVE OF GENDER AND RACE IN BRAZIL}

\begin{abstract}
The aim of this article was to discuss the issue of cultural diversity in Brazilian organizations, in the context of metallurgy and mining in relation to black woman in this space. The methodology applied was based on descriptive research of a qualitative and the speech analysis. Results: through the construction of the meaning of the subjects surveyed it showed the complexity of gender and race, in Brazilian organizations. Final considerations: the application of the theoretical basis based on the Organization defended by Baldissera $(2004 ; 2008 ; 2009 ; 2015)$ made it possible to demonstrate how complex the spoken and communicating organization is, such as studies on cultural diversity.
\end{abstract}

Keywords: Gender. Race. Organizational Communication. Black Woman. Management.

Perspectivas em Gestão \& Conhecimento, João Pessoa, v. 10, n. 1, p. 54-66, jan./abr. 2020

DOI: http://dx.doi.org/10.21714/2236-417X2020v10n1p54

http://periodicos.ufpb.br/ojs2/index.php/pgc. ISSN: 2236-417X. Publicação sob Licença (cc) EY-NC-ND 


\section{INTRODUÇÃO}

O estudo proposto buscou cobrir uma lacuna na produção acadêmica do campo da administração, devido à carência de estudos nessa área do conhecimento, contabilizando apenas oito artigos sobre a mulher negra no mercado de trabalho no Brasil (BENTO, 1995; FIGUEIREDO, 2008; ZAMORA, 2012; FERREIRA et al., 2015; DESOUZA, 2017; GOUVÊA, 2017; FERREIRA, 2018, MAIA et al., 2018). Destaca-se também que na esfera da comunicação no contexto das organizações, foi identificada, após acurada pesquisa bibliográfica, que apenas dois trabalhos tratam da diversidade de raça e gênero no ambiente organizacional no Brasil, na esfera da comunicação. Segundo Escosteguy e Messa (2006), existe baixa produção científica sobre essa temática no país. Assim pretende-se, neste artigo, associar ambas as questões: comunicação organizacional e a presença da mulher negra nesse mercado laboral. Apesar de ser um tema desafiador, ele permite diversas possibilidades e variações na interação da organização com os diversos públicos. O estudo traz como contribuição a sinergia dos pesquisadores das áreas: comunicação organizacional, administração e da linguística para a construção do signo mulher e negra.

O objetivo foi compreender os sentidos dados pelos sujeitos sobre a participação da mulher negra no mundo do trabalho, nas empresas de siderurgia/mineração no Brasil. Para tal alcance, traça-se um percurso metodológico de abordagem qualitativa e descritiva, com participação de profissionais que trabalham ou já trabalharam nesse segmento, por meio de questionário, tecnicamente denominado de bola de neve ${ }^{1}$. Para compreender os sentidos dados pelos sujeitos sobre a participação da mulher negra no mundo do trabalho, a base teórica refere-se às dimensões da organização de Baldissera (2008) e seu entendimento da comunicação organizacional como um "processo de construção e disputa de sentidos no âmbito das relações organizacionais" (BALDISSERA, 2008, p. 169).

Ferreira e Oliveira (2017) enfatizam que os processos da comunicação são delineados por dilemas situacionais como os conflitos de poder e as representações de papéis, demonstrando a complexidade da comunicação nas/das organizações. Entretanto, é por meio da comunicação que a estratégia da diversidade cultural é consolidada ao nível da organização comunicante e falada, e se configura como um desafio na inserção de grupos considerados minoritários, como negros e mulheres, no staff da empresa.

Assumindo esse entendimento, percebe-se que a inserção desses grupos minoritários, sem uma mudança cultural ou treinamento da equipe na organização, pode ocasionar baixo desempenho ou adoecimento (KOCHAN et al., 2003; BENDASSOLI, 2010). Muitas vezes, a discriminação pode decorrer de falhas nos processos de comunicação e na falta de comunicação. Entende-se, neste artigo, a diversidade cultural como meio de inclusão aos excluídos, dando-Ihes oportunidades para demonstrar suas diversas competências.

Como sujeito empírico deste estudo, a diversidade cultural nas organizações refere-se à questão de gênero e raça. $O$ gênero é considerado como construção sociocultural entre a diferenciação sexual, significando relações de poder, que são assimétricas e desiguais (SCOTT, 1994), e raça, como uma construção social, política ou cultural e não uma entidade biológica (PENA; BORTOLINI, 2004; DESOUZA, 2017) permeada por relações de poder e controle

\footnotetext{
${ }^{1}$ Snowball (Bola de Neve) é uma técnica de amostragem que utiliza cadeias de referência, uma espécie de rede, Essa técnica é uma forma de amostra não probabilística utilizada em pesquisas sociais onde os participantes iniciais de um estudo indicam novos participantes que por sua vez indicam novos participantes e assim sucessivamente, até que seja alcançado o objetivo proposto (o "ponto de saturação"). O "ponto de saturação" é atingido quando os novos entrevistados passam a repetir os conteúdos já obtidos em entrevistas anteriores, sem acrescentar novas informações relevantes à pesquisa (WHA,1994). WORLD HEALTH ASSOCIATION. Division of Mental Health. Qualitative Research for Health Programmes. Geneva: WHA, 1994.
}

Perspectivas em Gestão \& Conhecimento, João Pessoa, v. 10, n. 1, p. 54-66, jan./abr. 2020. 
econômico (WADE, 2017). Raça negra corresponde aos homens e às mulheres de cor preta ou parda, conforme classificação do Instituto Brasileiro de Geografia e Estatística (IBGE, 2014).

Esse estudo foi delineado em cinco seções: introdução, referencial teórico (constituído dos temas dimensões da organização na perspectiva comunicacional e diversidade e sua gestão no contexto das organizações), percurso metodológico, resultados e análise, considerações finais e referências bibliográficas.

\section{REFERENCIAL TEÓRICO}

Apresentam-se, nesta seção, os conceitos centrais que demonstram a criticidade da diversidade cultural nas organizações e como ocorre a comunicação organizacional para a construção de sentido pelos sujeitos sobre a mulher negra, dando subsídio para responder ao objetivo proposto.

\subsection{Dimensões da organização na perspectiva comunicacional}

Baldissera (2009) apresenta as três dimensões das organizações tensionadas e interdependentes: a) organização comunicada - fala autorizada, oficial e planejada; b) organização comunicante - fala autorizada e demais processos comunicacionais que se atualizam sempre que alguma pessoa estabelece uma relação direta com a organização, comunicação que se dá nas relações pessoais e públicas com a organização; e, c) organização falada - processos de comunicação referentes à organização, produzidos fora do seu ambiente.

A organização comunicada foi representada pelos procedimentos formais e disciplinadores da fala oficial. É aquilo que a organização escolhe para falar sobre si, por meio dos processos comunicacionais estratégicos ou não, que dá visibilidade, legitimidade e capital simbólico sobre si - reconhecimento, vendas, lucros, votos, dentre outros - voltados para a imagem e autoelogio (BALDISSERA, 2009; BALDISSERA; STOCKER, 2015; FERREIRA; OLIVEIRA, 2017).

A organização comunicante se configura como a comunicação que ocorre fora da esfera da fala autorizada, mas nos subterfúgios da organização, que está em constante transformação e atualização, de alguma maneira e em algum nível com pessoa ou grupo que estabelece relações com ela. Caracteriza-se em situações informais, sem que a organização tenha ciência do que está sendo falado. Nem sempre é o que a organização deseja comunicar, sendo que alguém atribui sentido e ocasiona disputa de sentidos, entre a organização comunicada e comunicante (BALDISSERA, 2009). Ressalta-se que, por sentidos, entende-se: "o processo social, historicamente localizado, que implica a mediação de vozes que se alternam entre as instâncias de produção, circulação e consumo, por meio de repertórios interpretativos, que, na dinâmica da alternância, atribuem significações àquilo que se apresenta" (OLIVEIRA; PAULA, 2011, p.98).

Por fim, a organização falada constitui um processo comunicacional informal e indireto, pois acontece fora do âmbito da organização, mas a ela se refere. Esse tipo de processo ocorre nas interações entre colegas e amigos, nos momentos de lazer ou descanso, nas relações familiares, nos processos especulativos, na escola, nos vizinhos, entre outros, e a organização não tem nenhum controle do que está sendo falado sobre ela (BALDISSERA; STOCKER, 2015; FERREIRA; OLIVEIRA, 2017).

O processo da comunicação organizacional é complexo e a dependência da organização comunicante e falada pode vir a interferir na imagem organizacional, comprometendo suas políticas.

Perspectivas em Gestão \& Conhecimento, João Pessoa, v. 10, n. 1, p. 54-66, jan./abr. 2020. 


\subsection{Diversidade e sua gestão no contexto das organizações}

O constructo diversidade é um termo complexo no âmbito organizacional, devido ao seu significado não ser imediato, nem unívoco. Essa falta de unicidade leva a diferentes tipos de abordagens sobre a temática (PEREIRA; HANASHIRO, 2007). Foi adotada a diversidade oriunda da identidade social, logo, relacionada com as diferenças entre grupos de pessoas (PEREIRA; HANASHIRO, 2007, LORENTZ, CARRIERI, MAESTRO FILHO, LIMA, 2016).

De acordo com Lorentz et al. (2016), a temática da diversidade organizacional não é transparente em termos de interdependência, no sentido que propicia a superioridade de um grupo sobre outro, sendo o discurso organizacional unilateral. A diversidade nas organizações não deve ser tolerada, mas compartilhada entre todos os funcionários, facilitando ou não o reconhecimento das diferenças como: raça, gênero, etnia e nacionalidade (COX JR, 1990, 1993; PEREIRA, HANASHIRO, 2007) e da maneira como a valorização das diferenças é direcionada para se buscar um consenso ou ordem social (LORENTZ et al., 2016).

Por isso, a diversidade é uma variável sujeita aos significados e valores culturais, os quais são atribuídos ao grupo, sendo que as diferenças entre as pessoas acontecem por meio das vantagens econômicas e de poder constituído no contexto histórico (PEREIRA; HANASHIRO, 2007).

Segundo Levrini e Papa (2016) e Hanashiro e Albuquerque (2017), a diversidade configurou-se em um dos desafios da gestão de pessoas, pois emergia a necessidade de preparar a área de recursos humanos para um fenômeno global, que desestruturou o modelo vigente baseado na uniformidade organizacional, quando todas as pessoas apresentavam um padrão igual, tanto nas funções quanto na maneira de agir. Carvalho-Freitas et al. (2017) consideram que, nos episódios contingenciais do trabalho, a diversidade é um fenômeno social, refletida no contexto organizacional.

Para Hanashiro e Carvalho (2005), Pereira e Hanashiro (2010), Cook e Glass (2014), Henderson, Ferreira e Dutra (2016), Jansen, Otten, Podsiadlowski e Zee (2016), Hanashiro e Albuquerque (2017), Franco, Magalhães, Paiva e Saraiva (2017), as práticas e políticas do gerenciamento da diversidade poderiam remediar ou fazer mudanças na posição histórica das mulheres nas empresas, ambientes de discriminação, devendo buscar competência e não a origem social, tampouco a questão de gênero, raça ou qualquer forma discricionária.

No entanto, a gestão da diversidade não dizimou o racismo institucional e a barreira do "teto de vidro" (BENTO, 1995; YAP, KONRAD, 2009; VRAVEC, BAČIK, 2012; COOK, GLASS, 2014; BAZAZO et al., 2017; MARRY, POCHIC, 2017; ARAÚJO, VASCONCELOS, 2018). Segundo Figueiredo (2008) e Coutinho et al. (2009), os indicadores sociais reforçam que o ambiente do trabalho não está preparado para a diversidade. Encontra-se uma força mútua entre o racismo e o sexismo ao ponto de grupos minoritários frequentarem outros espaços que não de seu grupo de origem. Portanto, há interseção entre gênero e raça e essas são categorias que interagem, produzindo oportunidades desiguais para sujeitos diferentes.

Para Coutinho et al. (2009), os programas de gestão da diversidade ficam a cargo das estratégias organizacionais e postulam que essas políticas de inclusão de grupos marginalizados estejam com matizes estereotipados interconectados com identidade étnica e hierarquizada, concluindo também que há discriminação de mulheres e afrodescendentes no processo de ascensão aos cargos de maior poder.

Como crítica, Alves e Galeão-Silva (2004) e Jansen et al. (2016) ressaltam que a gestão da diversidade é uma ideologia por não considerar as limitações referentes ao preconceito com a pessoa ou a grupos de pessoas discriminadas. Também ao fato de que muitas empresas utilizam o multiculturalismo como estratégia de comunicação organizacional, passando a ter um conceito de sustentabilidade, mas sem a premissa de discutir ou mesmo combater o

Perspectivas em Gestão \& Conhecimento, João Pessoa, v. 10, n. 1, p. 54-66, jan./abr. 2020. 
racismo institucional, uma vez que as empresas têm por meta maximizar a eficiência econômica e transformar as diferenças em vantagem competitiva.

Segundo Franco, Magalhães, Paiva e Saraiva (2017), o discurso da gestão da diversidade não passa de cumprimento de exigências legais e não tem por objetivo superar as desigualdades sociais. Portanto, a temática da diversidade apresenta diversas abordagens que acabam refletindo na organização e, consequentemente, na gestão da diversidade, que ainda não é consensual em termos de efetividade, justificando mais estudos empíricos para desmitificar preconceitos em relação à importância da inclusão das pessoas do grupo considerado minoritário.

\section{PERCURSO METODOLÓGICO}

O caminho metodológico adotado fundamenta-se, conforme mencionado, nas dimensões da organização, em acordo com Baldissera (2009). A dimensão comunicante foi representada pelos sujeitos que trabalham na siderurgia, e a falada, pelos profissionais que já trabalharam na mineração. $O$ estudo foi delineado a partir de uma abordagem qualitativa e descritiva (GIL, 2008), tendo como instrumento um questionário semiestruturado, enviado por e-mail, contendo cinco perguntas sobre gênero e raça no contexto das organizações e com possibilidade de interação com os autores, buscando maior profundidade. Foi utilizada a técnica snowball sampling, denominada no Brasil de Bola de Neve (VINUTO, 2014), que parte de um sujeito indicado e ao qual é solicitado que repasse o questionário a outras pessoas em potencial de sua network. As questões presentes no questionário foram:

1. Você percebe a diversidade cultural, em termos de gênero e raça, como um fator positivo para a empresa? Ou é apenas para ser sustentável? 2. Você percebe que as mulheres, independente da raça, são valorizadas igualmente na organização? 3. As mulheres têm a mesma oportunidade que os homens, para alçar o topo da organização? 4. A quantidade de mulheres negras na organização tem aumentado ou diminuído nos últimos cinco anos? 5. Há equidade salarial entre homens e mulheres, e entre mulheres brancas e negras, que estejam na mesma ocupação na organização?

Os respondentes que já trabalharam ou trabalham na siderurgia e metalurgia foram caracterizados dentro de variáveis demográficas, como: profissão, sexo, idade e escolaridade. Esse ramo de negócio foi escolhido porque há predominância de trabalhadores do sexo masculino, além do fato de ter a questão da diversidade muito frágil e pouco discutida nesses setores da economia. A mineração lida com a matéria prima bruta minério de ferro e a siderurgia transforma o minério de ferro em diversos tipos de aço.

Para análise das respostas dos sujeitos, foram utilizados parâmetros advindos da Análise do Discurso, aplicando a abordagem da referenciação, sob a perspectiva interacionistadiscursiva, considerando-se as dimensões pragmáticas, textuais e linguísticas de produção de sentido (MARCUSCHI, 2004; LOPES, 2004, 2017).

Antecipando o valor do discurso em uma situação real, Volóchinov (2017) afirma que qualquer enunciado real, em grau maior ou menor, e de um modo ou de outro, concorda com algo ou nega algo. Todo enunciado responde a algo e orienta-se para uma resposta. Ele é apenas um elo na cadeia ininterrupta de discursos verbais. "Todo monumento continua a obra de antecessores, polemiza com eles, espera uma compreensão ativa e responsiva" (VOLÓCHINOV, 2017, p. 184). Desse entendimento, a situação social mais próxima e o ambiente social mais amplo determinam completamente as demais, de dentro, a estrutura do enunciado (VOLÓCHINOV, 2017).

Carvalho Filho (2016, p.137), corroborando palavras de Goffman (2011), assegura que "os ritos de interação são ocasiões de afirmar a ordem moral e social. Num encontro face a face, cada ator social busca fornecer dele uma imagem valorizada, a 'face' ou 'valor social

Perspectivas em Gestão \& Conhecimento, João Pessoa, v. 10, n. 1, p. 54-66, jan./abr. 2020. 
positivo' que uma pessoa reivindica efetivamente através da linha de ação que os outros supõem que ele adotou no curso do contato particular".

As interações sociais envolvem sujeitos e por esta categoria sujeito entende-se todo agente capaz não somente de "apropriar-se da língua" para agir por meio dela (BENVENISTE, 1989; LOPES, 2004, 2017), mas de se constituir como sujeito pela linguagem (FRANCHI, 1992; POSSENTI, 1993; BRONCKART, 1999; LOPES, 2004, 2017). E é na análise dos processos constitutivos da referenciação, que os sujeitos constroem, por meio de práticas discursivas e cognitivas, social e culturalmente situadas, versões públicas do mundo, que sofrem transformações segundo contextos diferenciados. (LOPES, 2004, 2017).

O sentido da totalidade, para Volóchinov (2017), do enunciado foi chamado de tema. Ele expressa a situação histórica que gerou o enunciado. Para Ducrot (1984), sentido é a forma de representação do objeto. Esses conceitos são fundamentais na compreensão de um enunciado em dada situação social, conforme apresentado na situação empírica deste trabalho.

\section{RESULTADOS E ANÁLISES}

A partir da aplicação dos questionários, pôde-se levantar os seguintes dados da situação empírica. O conjunto de informantes apresenta apenas $12,5 \%$ de participação masculina, sendo $87,5 \%$ do sexo feminino, cujos enunciados foram tangenciados pelo contexto de produção discursiva, conforme se segue no quadro abaixo.

Quadro 1 - Variáveis demográficas e classificação dos sujeitos

\begin{tabular}{|c|c|c|c|c|c|c|}
\hline Dimensões & $\begin{array}{l}\text { Sujeitos } \\
\text { na ativa }\end{array}$ & Sexo & $\begin{array}{l}\text { Idade } \\
\text { (anos) }\end{array}$ & Escolaridade & Profissão & $\begin{array}{l}\text { Tipo de } \\
\text { empresa }\end{array}$ \\
\hline \multirow[t]{4}{*}{$\begin{array}{l}\text { Organização } \\
\text { comunicante }\end{array}$} & S1 & Homem & 26 a 35 & Mestrando & $\begin{array}{c}\text { Analista } \\
\text { Tributário }\end{array}$ & Siderurgia M \\
\hline & $\mathrm{S} 2$ & Mulher & 36 a 45 & Especialização/MBA & não respondeu & $\begin{array}{c}\text { não } \\
\text { respondeu }\end{array}$ \\
\hline & S3 & Mulher & 18 a 25 & Superior & comunicadora & Siderurgia M \\
\hline & S4 & Mulher & 46 a 60 & Mestrado & Psicóloga * & Mineração M \\
\hline \multirow[t]{5}{*}{$\begin{array}{l}\text { Organização } \\
\text { falada }\end{array}$} & $\begin{array}{c}\text { Sujeitos } \\
\text { que já } \\
\text { trabalhou }\end{array}$ & & & & & \\
\hline & S5 & Mulher & 26 a 35 & Mestrado & Administrador & Mineração M \\
\hline & S6 & Mulher & 26 a 35 & Especialização/MBA & Publicitária & Mineração M \\
\hline & S7 & Mulher & 46 a 60 & Mestrado & Geóloga & Mineração M \\
\hline & S8 & Mulher & 46 a 60 & Mestranda & $\begin{array}{l}\text { Relações } \\
\text { Públicas }\end{array}$ & Mineração M \\
\hline
\end{tabular}

Fonte: Elaboração própria.

Legenda: * Executiva RH. M- Multinacional.

Pelas respostas emitidas pelos informantes, o sujeito S1 evita o uso do advérbio não; apresenta asserções positivadas (forma de gestão corporativa; plano de carreira; meritocracia...); busca uma postura politicamente correta, sem se comprometer nas declarações (a mistura de raças nos traz diferentes tipos de convivência e de cultura; minimiza o preconceito contra as mulheres na gestão (ainda há um pouco de preconceito... na gestão de empresas); assertividade na igualdade de oportunidades (sim, aqui sim,...meritocracia) e no aumento de participação de mulheres na organização e equidade salarial decorrente de plano de carreira.

Perspectivas em Gestão \& Conhecimento, João Pessoa, v. 10, n. 1, p. 54-66, jan./abr. 2020. 
Em algumas respostas, houve apenas uso do advérbio não ou sim (S2, S3, S7), criando sentido de não querer explanar sobre a questão, como impossibilidade de falar. Segundo Ducrot (1984, p. 419), "desde que haja um ato de fala, um dizer, há uma orientação necessária para aquilo que não é o dizer. E esta orientação pode ser denominada de 'referência', chamando 'referente' o mundo ou objeto que ela pretende descrever ou transformar. 0 referente de um discurso não é assim, como por vezes se diz, a realidade, mas sim, a sua realidade, isto é, o que o discurso escolhe ou institui como realidade."

Ressalta-se que os informantes S1 e S3 encontram-se em atividade profissional, na área siderúrgica. S1, do sexo masculino, mestrando, analista tributário. A partir dessas variáveis classificatórias, nota-se que todo o posicionamento ideológico reflete e refrata a realidade que se encontra fora dos limites natural e social. Tudo o que é ideológico possui uma significação; ele representa e substitui algo encontrado fora dele, ou seja, ele é um signo; onde há signo, há ideologia. E os sujeitos S2 e S3, sexo feminino e com nível superior, sentiram-se impelidos a se manifestarem. Pode-se perceber que se se trata de um sujeito S1 envolvido, social e culturalmente ancorado, por meio da forma mais ou menos objetivada da versão do mundo que suas palavras produzem (VOLÓCHINOV, 2017). Já para S2 e S3, a palavra está sempre repleta de conteúdo e de significação ideológica ou cotidiana (VOLÓCHINOV, 2017).

Nota-se que os objetos do discurso são sensíveis à variação contextual, por essa razão podem ser enriquecidos, alimentados e construídos coletivamente pelos locutores, uma vez que os depoimentos da informante $\mathrm{S} 8$ exemplificam a atividade referencial como uma atividade de natureza inferencial, decorrente do diálogo entre linguagem e mundo. Esse diálogo reflete, por meio das escolhas lexicais, do repertório vocabular, coerência, enquadramento tópico, conhecimentos partilhados, interação, efeitos de sentido e atividades cognitivas (MONDADA; DUBOIS, 2003).

É interessante salientar a diferença no posicionamento da informante S8, S4 e S5 em relação ao informante $\mathrm{S} 1$, em todas as questões do questionário. $\mathrm{S} 8$ enfatiza que a postura 'politicamente correta' é que mobiliza a organização a incluir questões de gênero e raça nas empresas de mineração, em busca de credibilidade, reputação, selo de responsabilidade social, conforme este excerto apresenta: "a adoção dessa prática está muito mais relacionada à construção de uma imagem e reputação apropriada, condizente com que é moral e eticamente demandado pela sociedade, do que por uma crença real". "Percebo como um fator positivo, embora em posições executivas ou que requeiram um nível de escolaridade mais alto, mulheres e, mais ainda, negras são minoria". "Há poucas mulheres negras na organização, e a maioria está em cargos técnicos" (S4). "Mas de fato os brancos são a maioria. E a maioria dos negros e pardos estão nas áreas operacionais. No entanto, no Brasil, há um diretor negro e na África do Sul, onde a maioria são negros, tanto nos cargos de liderança quanto nos cargos intermediários e operacionais" (S6). "Eu saí da empresa há três anos, e até aquela época era apenas para ser sustentável; a diversidade de gênero não era bem vista, uma vez que nem as mulheres eram muito bem aceitas naquele ambiente de trabalho" (S5).

Em relação à valorização igual entre homens e mulheres, ao contrário do informante S1 e S4, S8 não titubeia na resposta, ao assegurar que "muito pelo contrário, elas são desvalorizadas pelo seu gênero. Em especial, em segmentos de negócios que, "culturalmente", são considerados como masculinos, como a mineração, a metalurgia, a siderurgia, entre outros. [...] é notório que o número de mulheres que ocupam cargos do tipo gerencial/executivo é menor. "Nem sempre. Ainda há um pouco de preconceito, principalmente quando as mulheres têm cargo de gestão" (S1). "Mulheres não são valorizadas igualmente. Os homens têm salários mais altos e em muitas posições - especialmente as que são diretamente ligadas à operação e a cargos do alto escalão - são preferidos" (S4).

Sobre as oportunidades de as mulheres alcançarem o gerenciamento de empresas na área da mineração, S8, S7, S6 e S4 trazem relevante leitura sobre as avaliações que os homens

Perspectivas em Gestão \& Conhecimento, João Pessoa, v. 10, n. 1, p. 54-66, jan./abr. 2020. 
fazem da postura gestora das mulheres, por meio de piadas de mau gosto, ao afirmarem que "quanto às que chegam, costumam ser mal vistas, e, vez ou outra, são alvo de piadas de gosto duvidoso: "está de tpm", "é mal-amada", ou parece "homem". "Isso ainda é comum no ambiente empresarial". "Percebo que as mulheres não são valorizadas igualmente" (S6). "Existe o discurso, mas não a ação. Há mais mulheres em posição de chefia, mas ainda são poucas percentualmente" (S7). "Mulheres não são valorizadas igualmente. Os homens têm salários mais altos e em muitas posições - especialmente as que são diretamente ligadas à operação e cargos do alto escalão - são preferidos" (S4); "A mulher não tem a mesma oportunidade. Existem candidatas internas em número menor para concorrer, isso porque o processo de seleção externo já filtra na entrada. Também há uma predileção por homens no primeiro e segundo nível de liderança" (S4).

Portanto as relações de poder emaranhadas com os sentidos da comunicação demonstram a fragilidade da organização comunicada em relação à questão de gênero. Nos discursos percebe-se a presença do poder como norteador das assimetrias dos sentidos e a acepção jocosa produzida no ambiente organizacional quando as mulheres conseguem posições mais altas na estrutura de poder. A ruptura de situações históricas nas organizações demanda estratégias específicas, mudança de sentidos em reconhecer a capacidade do outro no processo (BALDISSERA, 2004).

Na perspectiva de Baldissera e Stocker (2015), nem sempre os discursos condizem com a prática, devido ao processo de construção e disputa de sentidos nas relações organizacionais. Os discursos presentes na organização falada convergem com os discursos sociais da organização comunicante sobre a dificuldade de a mulher negra chegar ao topo das organizações. "A mulher não tem a mesma oportunidade. Existem candidatas internas em número menor para concorrer, isso porque o processo de seleção externo já filtra na entrada. Também há uma predileção por homens no primeiro e segundo nível de liderança" (S4).

Quanto ao aumento ou não da presença das mulheres na área da mineração, conforme já citado, S1 foi categórico e objetivo ao afirmar que o número tem aumentado, enquanto que $\mathrm{S} 8$ acrescenta e reforça que essa pseudoinclusão deve-se à obrigatoriedade legal e social que as empresas têm em relação a esse problema: Pressuponho que o número esteja crescendo, em função da própria demanda do mundo corporativo, que vem adotando, de forma cada vez mais intensa, relatos que divulgam suas práticas gerenciais, números relativos à contratação de profissionais portadores de necessidades especiais, diversidade de gêneros, raça, bem como posição destes em cargos de chefias".

Por fim, em relação à equidade salarial relativa à cor, $\$ 8$ afirma acreditar em desnível, com possibilidade de mascaramento de dados pelas empresas, conforme se segue: "penso que existe uma desigualdade significativa, tanto entre homens, e mulheres e uma desigualdade sensível entre mulheres brancas e negras na mesma posição. As diversas variáveis relativas às faixas de salário em uma mesma posição devem colaborar para "mascarar" essa realidade. "Não, com certeza não. Mesmo que as pessoas exerçam a mesma função, há diferenças salariais, acontece que não há explicação formal para tal fato na empresa" (S5); "Não. E há de se reparar que, num período de crise e cortes, mais mulheres negras foram demitidas. Isso serve para a comparação com homens brancos" (S7). Nesse sentido, essas opiniões reforçam que o mundo de nosso discurso é sociocognitivo e produzido, por que é o lugar privilegiado da organização desse mundo (LOPES, 2004).

Pôde-se perceber que o sentido da totalidade do enunciado, de fato passou a ser configurado como tema, conforme as lições de Volóchinov (2017), porque essa categoria expressa a situação histórica que gerou o enunciado. Para Ducrot (1984), sentido é a forma de representação do objeto. Nesse sentido, nota-se que, por meio dos enunciados dos informantes, suas posições sociais, e suas assertividades, é possível depreender as concepções

Perspectivas em Gestão \& Conhecimento, João Pessoa, v. 10, n. 1, p. 54-66, jan./abr. 2020. 
que trazem para o espaço feminino, da raça negra nos espaços organizacionais da siderurgia, ainda muito discriminatório.

\section{CONSIDERAÇÕES FINAIS}

O objetivo deste estudo foi compreender os sentidos dados pelos sujeitos sobre a participação da mulher negra no mundo do trabalho nas empresas de siderurgia/mineração no Brasil.

O quadro de análise explorado no corpus possibilitou apresentar a dimensão discursiva da atividade referencial decorrente das relações intersubjetivas instauradas pelos interlocutores mediante os recursos linguísticos (MARCUSCHI, 2004). Por meio dos discursos, que são atividades de enunciação em condições históricas e sociais, que torna a interação uma matriz de sentidos, ideologicamente construídos, decorrente da posição social, histórica e cultural de cada ser humano em seu contexto/realidade concreta, pôde-se perceber escolhas ideológicas dos participantes da pesquisa, os quais, por meio das escolhas linguísticasdiscursivas, manifestaram opiniões que incluem elou excluem a participação da mulher negra nas organizações da siderurgia (VOLÓCHINOV, 2017).

Foram aplicadas na análise as duas dimensões do processo comunicacional das organizações, propiciando a compreensão de sentido a partir da complexidade da diversidade cultural relativas a gênero e raça na siderurgia e metalurgia, expandindo a discussão entre o que é dito informal e os fatos. Percebe-se que a mulher negra tem maior dificuldade de ser reconhecida no mercado profissional dos setores analisados e que sofre discriminação nesse ambiente organizacional. $\mathrm{O}$ campo da comunicação deve voltar o olhar para esse conflito e contribuir com estratégias que possam fomentar as organizações a repensar a questão de gênero e raça nos seus processos interacionais e administrativos internos.

Ressalta-se a relevância do estudo apresentado, por se tratar de uma tentativa de articulação entre os conceitos desenvolvidos por Baldissera sobre as dimensões das organizações na perspectiva da comunicação e a questão da diversidade cultural em termos de raça e gênero na perspectiva da administração, configurando-se em uma questão contemporânea para as organizações.

A estratégia da diversidade cultural deve ser estimulada pela sociedade e pelo governo para aumentar a participação de mulheres negras no quadro de pessoal e reduzir a desigualdade social. Percebe-se o sexismo e o racismo como impedimentos para o crescimento na carreira profissional, além de representarem uma dificuldade que as organizações precisam resolver para atender a uma demanda social mais justa. É complexo o processo da comunicação organizacional e a dependência da organização comunicante e falada, porque ela pode vir a interferir na imagem da organização, comprometendo suas políticas e estratégias.

Em relação às contribuições deste estudo, pode-se afirmar que esta discussão preenche uma lacuna no campo da comunicação organizacional e da administração por esses campos não refletirem, sistematicamente, as questões de gênero e raça presentes no mundo organizacional, sobretudo com a sinalização de pistas de que já está ocorrendo mudança em relação à equidade salarial entre mulher branca e negra. No entanto, é necessário ampliar o debate e os estudos sobre a temática na perspectiva comunicacional e na esfera de gestão de pessoas, além de lutar para que a mulher possa alcançar posições de destaque profissional nessas organizações, tendo a mesma equidade salarial dos homens brancos.

Como sugestões do estudo, além da reflexão produzida pela pesquisa descritiva e as construções de sentido dos sujeitos empíricos, reais do estudo, levantam-se as seguintes indagações: Por que o efetivo de trabalhadores na área da siderurgia não é multicultural? Por que há tanta dificuldade para vencer o preconceito racial e sexista nas organizações? Por que ainda há poucas mulheres no poder no setor de mineração?

Perspectivas em Gestão \& Conhecimento, João Pessoa, v. 10, n. 1, p. 54-66, jan./abr. 2020. 


\section{REFERÊNCIAS}

ALVES, M. A.; GALEÃO-SILVA, L. G. A crítica da gestão da diversidade nas organizações. RAERevista de Administração Eletrônica, v. 44, n. 3, p. 20-29, 2004.

ARAÚJO, F. S.; VASCONCELLOS, B. M. Vivenciando o ser mulher em uma mina de carvão. Revista Estudos Feministas, v. 26, n. 1, e44967, January 2018. Disponível em: http://dx.doi.org/10.1590/1806-9584.2018v26n144967. Acesso em 02 out. 2019.

BALDISSERA, R. Imagem-conceito: anterior à comunicação, um lugar de significações. 2004. Tese (Comunicação Social) - Pontifícia Universidade Católica de do Rio Grande do Sul, Porto Alegre, Brasil, 2004.

BALDISSERA, R. Comunicação organizacional: uma reflexão possível a partir do paradigma da complexidade. In: OLIVEIRA, I. L.; SOARES, A. T. N. (org.). Interfaces e tendências de comunicação no contexto das organizações. São Caetano do Sul, SP, Difusão, 2008.

BALDISSERA, R. Comunicação organizacional na perspectiva da complexidade. Organicom, v. 6, n. 10/11, p.115-120,2009.

BALDISSERA, R.; STOCKER, P. Comunicação organizacional e Ethos discursivo: estratégias para falar de si nos anúncios dos bancos. In: MARQUES, Â.C.S.; OLIVEIRA, I. L. (org.). Comunicação organizacional: dimensões epistemológicas e discursivas. Belo Horizonte: Ed. Fafich, UFMG, 2015.

BAZAZO, I.; NASSEEF, M. A.; MUKATTESH, B.; KASTERO, D.; AL-HALLAQ, M. Assessing the glass ceiling effect for women in tourism and hospitality. Journal of Management and Strategy, v. 8, n. 3, p. 51-66, junho 2017.Disponível em: http://dx.doi.org10.5430/ jms. v8n3p51. Acesso em 02 out. 2019.

BENDASSOLI, P. F. O culto à performance como resposta à crise da ontologia do trabalho. In: Ehrenberk, A. $\mathbf{O}$ culto da performance: da aventura à depressão nervosa. Aparecida, SP, Ideias \& Letras, 2010.

BENTO, M.A.S. A mulher negra no mercado de trabalho. Estudos feministas, v. 3, n. 2, p. 479488, 1995.

BENVENISTE, É. Problemas de Lingüística Geral II. 3. Ed. Campinas, SP: Pontes, 1989.

BRONCKART, J.P. Atividade de linguagem, textos e discursos - por um interacionismo sóciodiscursivo. São Paulo: EDUC, 1999.

CARVALHO FILHO, J.L. Rituais de interação na vida cotidiana: Goffman, leitor de Durkheim. Política \& Sociedade, v.15, n.4, p.137-159, 2016. Disponível em: http://dx.doi.org/10.5007/2175-7984.2016v15n34p137. Acesso em 02 out. 2019.

CARVALHO-FREITAS, M.N.; SILVA, O. A.; TETTE, R.P. G.; SILVA, C.V. Diversidade em contextos de trabalho: pluralismo teórico e questões conceituais. Revista Economia \& Gestão, v. 17, n. 48, p. 174-191, set./ dez. 2017.

Perspectivas em Gestão \& Conhecimento, João Pessoa, v. 10, n. 1, p. 54-66, jan./abr. 2020. 
COOK, A.; GLASS, C. Women and top leadership positions: towards and institutional analysis. Gender, Work and Organization, v.21, n.1, p. 91-103, 2014.

COUTINHO, L.R.S.; COSTA, A.M.; CARVALHO, J. L. F. S. Debatendo diversidade de gênero e raça no contexto organizacional brasileiro: lei do mercado ou cotas por lei? Sociedade, Contabilidade e Gestão, v.4, n.1, p.21-37, 2009.

COX JR, T. Cultural Diversity in Organizations: Theory, Research and Practice. San Francisco: Berrett-Koehler Publishers,1990,1993.

DESOUZA, E.M. Processos de radicialização: inteligibilidade, hibridade e identidade racial em evidência. E\& G- Economia \& Gestão, v.17, n.48, p.23-42, set./dez. 2017.

DUCROT, O. Referente. In. Enciclopédia Einaudi: linguagem e enunciação. Lisboa, Imprensa Nacional - Casa da Moeda, v.2, p.418- 438,1984.

ESCOSTEGUY, A.C.D.; MESSA, M.R. Os estudos de gênero na pesquisa em comunicação no Brasil. Contemporânea, v.4, n.2, p.65-82, 2006.

FERREIRA, D.A.; OLIVEIRA, I.L. Entrelaçando os conceitos de dimensões das organizações e estruturas de participação de Goffman. Organicom, v.14, n.26, p.324-333, 2017.

FERREIRA, J.B.; SADOYAMA, A.S.P.; CORREIA, A.F.C.; GOMES, P.A.T.P. Diversidade e gênero no contexto organizacional: um estudo bibliométrico. Revista Pensamento Contemporâneo em Administração, v.9, n.3, p.45-66, 2015.

FERREIRA, L. Menos de $3 \%$ entre docentes na pós-graduação, doutoras negras desafiam o racismo na academia, junho 2015. Disponível em: http://www.generonumero.media/menosde-3-entre-docentes-doutoras-negras-desafiam-racismo-na-academia/. Acesso em 20 nov. 2018.

FIGUEIREDO, A. Gênero. Dialogando com os estudos de gênero e raça no Brasil. In: SANSONE, L.; PINHO, O.A. Raça: novas perspectivas antropológicas (orgs). Salvador: Associação Brasileira de Antropologia: EDUFBA, 2008.

FRANCHI, C. Linguagem - Atividade Constitutiva. Cadernos de Estudos Lingüísticos, v.22, p. 939, 1992.

FRANCO, D.S.; MAGALHÃES, A.F.; PAIVA, K.C.M.; SARAIVA, L.A.S. Entre a inserção e a inclusão de minorias nas organizações: uma análise crítica sob o olhar de jovens trabalhadores. E\&G Economia e Gestão, v.17, n.48, p.4-22, set./dez. 2017. Disponível em: https://doi.org/10.5752/P.1984-6606.2017v17n48p43-61. Acesso em 03 out. 2019.

GIL, A.C. Métodos e Técnicas de Pesquisa Social. 6. ed. São Paulo, Atlas, 2008.

GOFFMAN, E. Ritual de interação: ensaios sobre o comportamento face a face. Petrópolis: Vozes, 2011.

GOUVÊA. J.B. O que há por trás do discurso da harmonia racial da miscigenação. Farol- Revista de estudos organizacionais e sociedade, v.4, n.10, p. 915-955, ago. 2017.

Perspectivas em Gestão \& Conhecimento, João Pessoa, v. 10, n. 1, p. 54-66, jan./abr. 2020. 
HANASHIRO, D. M. M.; CARVALHO, S. G. Diversidade cultural: panorama atual e reflexões para a realidade brasileira. REAd - Revista Eletrônica de Administração, v.11, n.5, p.1-21, set./out 2005.

HANASHIRO, D.M.M.; ALBUQUERQUE, M. Apreciando similaridades e valorizando diferenças: um estudo sobre atitudes de gestores em relação ao discurso. E\&G Economia e Gestão, v.17, n.48, p. 4-22, set./dez. 2017.

HENDERSON, P.A.; FERREIRA, M. A. A.; DUTRA, J.S. As barreiras para a ascensão da mulher a posições hierárquicas; um estudo sob a óptica da gestão da diversidade no Brasil. Revista de Administração da UFSM, v.9, n.3, p.489-505,2016.

INSTITUTO BRASILEIRO DE GEOGRAFIA E ESTATÍSTICA (IBGE). Estatísticas de Gênero. Uma análise dos resultados do censo demográfico 2010. Estudos \& Pesquisas, 33, 2014, Rio Janeiro: IBGE.

JANSEN, W. S.; VOS, M.W.; OTTEN, S.; PODSIADLOWSKI, A.; VAN DER ZEE, K.I. Colorblind or colorful? How diversity approaches affect cultural majority and minority employees. Journal of Applied Social Psychology, v.46, n.2, p.81-93, 2016.

KOCHAN, T.; BEZRUKOVA, K.; ELY, R.; JACKSON, S; JOSHI, A.; JEHN, K. et al. The effects of diversity on business performance: report of the diversity research network. Human Resource Management, v.42, n.1, p. 3-21, 2003.

LEVRINI, G.R.D.; PAPA, A.P. A Obesidade nas Organizações: o Preconceito não Declarado. Organizações em Contexto, 12(24), 65-191, jul./dez. 2016.

LOPES, M.Â.P. T. Referenciação e gênero textual - atividades sócio-discursivas em interação. In: MACHADO, I. L.; MELLO, R. (Org.), Gêneros: reflexão em análise do discurso. Belo Horizonte, NAD/POSL in. FALE/UFMG, 2004.

LOPES, M.Â. P. T. Eventos de leitura no espaço acadêmico - representações sociais no processo de referenciação do gênero charge. In: BARROS, E. M. D.; STORTO, L. J. (org.), Gêneros do jornal e ensino: práticas de letramentos na contemporaneidade. São Paulo: Pontes,2017.

LORENTZ, C.N.; CARRIERI, A.P.; MAESTRO FILHO, A.D.; LIMA, L.C. Diversity recognition of the difference or tolerated difference/ A study on the perception of mining and steel professionals. Revista de Administração Mackenzie, v.17, n.4, p.39-61, jul/aug. 2016.

MAIA, K.; CATELAN, D.W.; BACCHI, M.D.; FONSECA, M.R. Diferenças salariais e discriminação por gênero e cor no mercado de trabalho da região sul do Brasil. Revista Estudo \& Debate, v.25, n.1, p.7-31, 2018. Disponível em: http://dx.doi.org/10.22410/issn.1983036X.v25i1a2018.1351. Acesso em 03 out. 2019.

MARCUSCHI, L.A. O léxico: lista, rede ou cognição social? In: NEGRI et al., (Org.). Sentido e Significação, Em torno da obra de Rodolfo llari. São Paulo: Contexto, 2004.

MONDADA, L.; DUBOIS, D. Construção dos objetos de discurso e categorização: uma abordagem dos processos de referenciação. In: CAVALCANTE, M.M.; RODRIGUES, B.B.; CIULLA, A. (org.). Referenciação. São Paulo: Contexto, 2003.

Perspectivas em Gestão \& Conhecimento, João Pessoa, v. 10, n. 1, p. 54-66, jan./abr. 2020. 
OLIVEIRA, I.L.; PAULA, C. F. Caetano de. Comunicação no contexto das organizações: produtora ou ordenadora de sentidos? In: OLIVEIRA, I.L.; SOARES, A.T. N. (Org.). Interfaces e tendências de comunicação no contexto das organizações. 2. ed. São Caetano do Sul, SP: Difusão Editora; Rio de Janeiro: Editora Senac Rio,2011.

PENA, S. J.; BORTOLINI, M.C. Pode a genética definir quem deve se beneficiar das cotas universitárias e demais ações afirmativas? Estudos Avançados, v.18, n.50, p. 31-50, 2004.

PEREIRA, J. B. C.; HANASHIRO, D. M. M. A gestão da diversidade: uma questão de valorização ou de dissolução das diferenças? In: ENCONTRO DA ANPAD, 31., 2007. Anais [...]. EnANPAD 2007, Rio de Janeiro.

PEREIRA, J. B. C., \& HANASHIRO, D. M. M. Ser ou não ser favorável às práticas de diversidade? Eis a questão. RAC - Revista de Administração Contemporânea, v.14, n.4, p.670-683, jul./ago. 2010.

POSSENTI, S. Discurso, estilo e subjetividade. São Paulo: Martins Fontes, 1993.

SCOTT, J. W. Preface a gender and politics of history. Cadernos Pagu, v.3, p.11-27,1994.

VINUTO, J. A amostragem em bola de neve na pesquisa qualitativa: um debate em aberto. Temáticas, v.22, n.44, p.203-220, 2014.

VOLÓCHINOV, V. Marxismo e filosofia da linguagem: problemas fundamentais dos métodos sociológicos na ciência da linguagem. São Paulo: Editora 34, 2017.

VRAVEC, J.; BAČIK, R. Discrimination of women in the labour market of sr and models of discrimination. Polish Journal of Management Studies, v.5, p.280-293, 2012.

WADE, P. Debate do professor Wade com convidados do PPGCS-UFBA. In: HITA, M. G., (org.). Raça, racismo e genética em debates científicos e controvérsias sociais. Salvador: EDUFBA,2017.

YAP, M.; KONRAD, A.M. Gender and racial differentials in promotions: is there a sticky floor, a mid-level bottleneck, or a glass ceiling? Industrial Relations, v.64, n.4, p.593-619, 2009.

ZAMORA, M.H.R.N. Desigualdade racial, racismo e seus efeitos. Fractal, Revista de Psicologia, v.24, n.3, p.563-578, set./dez. 2012. Disponível em: http://dx.doi.org/10.1590/S198402922012000300009. Acesso em 03 out. 2019.

WORLD HEALTH ASSOCIATION. Division of Mental Health. Qualitative Research for Health Programmes. Geneva: WHA, 1994.

Artigo recebido em 03/10/2019 e aceito para publicação em 10/04/2020 